\title{
Design and Build an IoT Based Prepaid Water Usage Monitoring System and Telegram Notifications
}

\section{Rancang Bangun Sistem Monitoring Pemakaian Air Prabayar Berbasis IoT dan Notifikasi Telegram}

\author{
Agus Priyanto ${ }^{1}$, Sabar Setiawidayat ${ }^{2}$, Faqih Rofii ${ }^{3}$ \\ ${ }^{1,2,3}$ ) Electrical Engineering, Faculty of Engineering, Widyagama University Malang, Malang, Indonesia \\ 1) aguspriyanto095@gmail.com \\ 2) sabarset@yahoo.com \\ 3) faqih@widyagama.ac.id
}

\begin{abstract}
The existence of a boarding house business has resulted in the existence of an outer bathroom boarding room (K3ML) and an inner bathroom boarding room (K3MD). In the case of K3MD business, there is the use of bathroom water which is included in the room rent and some is paid. In the case of paid K3MD, monitoring is needed to determine the amount of water used in each boarding room. This study aims to design a monitoring tool for the amount of water usage that can be monitored at any time by the owner of the boarding house and the occupants of the boarding house using a smartphone. The water discharge through the Flow Meter sensor then passes through the Solenoid Valve then is displayed on the 16X2 LCD and Telegram provides notification information when the water capacity of the boarding house occupants is nearing the end via a smartphone. If the quota runs out, the boarding house residents can buy the added boarding house via the web server. The data generated by the Flow Meter Sensor was tested for a size comparison with a measuring cup using the Independent Sample T-Test method with the SPSS application. This system can make it easier for boarding house owners to monitor the water usage of each boarding house occupant and there is no equalization of payments for each boarding room.
\end{abstract}

Keyword: Water Monitoring; Flow Meter Sensors; Telegram Bots.

Abstrak. Adanya usaha indekos menyebabkan adanya kamar kos kamar mandi luar (K3ML) dan kamar kos kamar mandi dalam (K3MD). Dalam hal usaha K3MD, terdapat penggunaan air kamar mandi yang sudah termasuk sewa kamar dan ada pula yang berbayar. Dalam hal K3MD yang berbayar maka dibutuhkan monitoring untuk mengetahui jumlah pemakaian air setiap kamar kos. Penelitian ini bertujuan untuk mendesain alat monitoring jumlah pemakaian air yang dapat dipantau setiap saat oleh pemilik rumah kos maupun penghuni kos menggunakan smartphone. Debit air melalui sensor Flow Meter lalu melewati Solenoid Valve kemudian ditampilkan pada LCD 16X2 dan Telegram memberikan informasi notifikasi apabila kapasitas air penghuni kos mendekati habis melalui smartphone. Apabila kuota habis, penghuni kos dapat membeli kepada pemilik kos yang ditambahkan melalui web server. Data yang dihasilkan oleh Sensor Flow Meter dilakukan uji komparasi besaran dengan gelas ukur menggunakan metode Independen Sample T-Test dengan aplikasi SPSS. Sistem ini dapat memudahkan pemilik kos untuk memonitoring pemakaian air setiap penghuni kos dan tidak ada penyamarataan pembayaran setiap kamar kos.

Kata kunci: Monitoring Air; Sensor Flow Meter; Telegram Bot. 


\section{PENDAHULUAN}

Adanya usaha indekos menyebabkan adanya kamar kos kamar mandi luar (K3ML) dan kamar kos kamar mandi dalam (K3MD). Dalam hal usaha K3MD, terdapat penggunaan air kamar mandi yang sudah termasuk sewa kamar dan ada pula yang berbayar. Kebutuhan pemakaian air tiap penghuni kamar berbeda-beda dalam suatu rumah kos. Sehingga menimbulkan masalah penyamarataan pembayaran setiap kamar kos dan penghuni kos dirugikan terkait pembagian beban tarif [1].

Dalam hal K3MD yang berbayar maka dibutuhkan memonitoring pemakaian air. Apabila sistem ini digunakan oleh pemilik kos, akan memudahkan pemilik kos dalam memberikan pelayanan kepada penghuni kos. Inovasi ini dilakukan agar penghuni kos mendapat kenyamanan dalam transaksi pembayaran pemakaian air, tetapi dengan menggunakan sistem prabayar, penghuni kos dengan mudah dapat mengisi jumlah air yang digunakan untuk keperluan seharihari, sistem ini dibuat untuk memonitoring pemakaian airrsecara realtime. Debit air diukur menggunakan sensor, kemudian diproses mikrokontroler yang ditampilkan aplikasi pada smartphone, serta memberikan sinyal pemberitahuan kepada pelanggan melalui Telegram apabila air akan habis. Perangkat ini diharapkan pemilik rumah dan penghuni kamar kos tidak dirugikan karena pemakaian air dapat di monitoring [2].

Telegram merupakan aplikasi layanan pengirim pesan instan seperti teks, foto, video dan dokumen. Telegram tersedia pada smart phone, tablet, computer. Telegram dapat digunakan pada multi platform dan dapat digunakan secara gratis [3]. Keunggulan dari Telegram tidak membebani memori. Di aplikasi lain, file yang dibagikan tersimpan pada media penyimpanan. Tetapi file di Telegram tersimpan selamanya pada server dan tidak terhapus kecuali file dihapus.

Internet of Things merupakan pengendalian komunikasi data melalui jaringan internet. IoT berkembang dari konvergensi $M E M S$ dan Internet pada jaringan nirkabel [4]. Perangkat elektronik nantinya akan berkomunikasi secara mandiri, menerima dan mengirimkan data melalui koneksi jaringan. MySQL merupakan sistem pengolah database didalam website, maka pemilik kos membutuhkan sistem pelayanan berbasis teknologi untuk memudahkan penghuni kos mendapatkan informasi pelayanan [5]. Sistem ini dikembangkan untuk memantau pemakaian air kemudian dapat di monitor dan dikendalikan oleh smartphone android [6].

Menyikapi dari permasalahan diatas, untuk kepentingan penghuni kos maka pemilik kos akan membuat monitoring pemakaian air prabayar berbasis IoT dengan notifikasi telegram. Alat ini dapat memberikan kemudahan bagi pemilik kos dan penghuni kos dalam mendapatkan informasi tentang pelayanan serta mampu memberikan sinyal pemberitahuan langsung pada penghuni kos melalui aplikasi mobile chat Telegram Group.

\section{DASAR TEORI}

\section{Internet of Things}

IoT merupakan pengendalian komunikasi data melalui jaringan internet. IoT bertujuan memperluas koneksi internet yang terhubung secara real time. IoT dikenal pada tahun 1999 yang disebutkan didalam presentasi Kevin Ashton, cofounder and executive director of the Auto-ID Center di MIT [4]. Internet of Things dapat dilihat pada Figure 1.

[Figure 1 about here.]

\section{Solenoid valve}

Solenoid valve merupakan katup yang dikendalikan arus listrik AC/DC melalui selenoida [7]. Solenoid valve mempunyai lubang keluaran, masukan dan exhaust. Solenoid valve berfungsi untuk membuka/menutup laju air yang dikontrol oleh Arduino. Solenoid valve dapat dilihat pada Figure 2.

[Figure 2 about here.]

\section{ESP8266 Wemos D1}

ESP8266 merupakan papan mikrokontoler yang dirancang oleh Wemos.cc dengan desain mirip Arduino Uno. Kelebihan ESP8266 adalah pengunaan daya yang efisien. Modul Wifi ESP8266-12E memiliki prosesor 32bit / 80-160MHZ, flash/program memori 4MB, SRAM 32KB \& DRAM 80KB, dengan fitur Wifi 2,4GHZ menjadikan Wemos D1 Wifi Arduino ESP826 sebagai board yang powerfull dan 


\section{J \\ ISSN 2460-9250 (print), ISSN 2540-8658 (online) \\ Vol. 5, No. 2, October 2021}

cocok untuk Internet of Things [8]. ESP8266 Wemos

D1 dapat dilihat pada Figure 3.

[Figure 3 about here.]

\section{Buck Converter LM 2596}

Rangkaian pengatur switching step-down yang mudah dan aman, serta tidak memerlukan transformer. Perangkat ini berfungsi untuk meminimalkan jumlah komponen eksternal dan menyederhanakan desain catu daya. Konverter LM2596 merupakan power supply switch-mode, yaitu efisiensi secara signifikan lebih tinggi dibandingkan regulator linier tiga terminal, dengan voltase masukan yang tinggi [9]. Buck Converter LM 2596 dapat dilihat pada Figure 4.

[Figure 4 about here.]

\section{Arduino Nano}

Arduino Nano adalah satu papan sirkuit berukuran kecil yang sudah terpasang mikrokontroler serta didukung penggunaan breadboard. Arduino Nano diciptakan dengan basis mikrokontroler ATmega 328 (untuk Arduino Nano versi 3.x) atau ATmega 168 (untuk Arduino versi 2.x). Arduino Nano memiliki fungsi yang sama dengan Arduino Duemilanove, tetapi dalam paket berbeda. Arduino Nano memiliki 8 pin sebagai input analog, diberi label A0 sampai A7, menyediakan resolusi 10 bit (yaitu 1024 nilai yang berbeda). Arduino Nano dibuat dan diproduksi oleh Gravitech [10]. Arduino Nano dapat dilihat pada Figure 5.

[Figure 5 about here.]

\section{LCD (Liquid Crystal Display)}

LCD adalah komponen untuk menampilkan data yang diproses mikrokontroler. LCD merupakan pengganti dari tampilan seven segment di mana LCD mempunyai kelebihan yaitu, bentuk tampilan bagus, hemat energi, dan dari segi bentuk lebih kecil [11]. LCD dapat dilihat pada Figure 6.

[Figure 6 about here.]

\section{Sensor Flow Meter}

Sensor aliran adalah untuk mengukur laju air dan gas, baik bertemperatur rendah hingga temperatur tinggi [7]. Sensor flow meter dapat dilihat pada Figure 7.
[Figure 7 about here.]

\section{Aplikasi Telegram Chat}

Telegram merupakan aplikasi layanan pengirim pesan instan seperti teks, foto, video dan dokumen. Telegram tersedia pada smart phone, tablet, computer. Telegram dapat digunakan pada multi platform dan dapat digunakan secara gratis. Telegram mendukung panggilan suara yang telah di enkripsi end-to-end sebagai keamanan tambahan [3]. Telegram dapat dilihat pada Figure 8.

[Figure 8 about here.]

\section{Database MySQL}

MySQL adalah sistem pengelolah database didalam website. MySQL merupakan program pengakses database yang bersifat jaringan, sehingga dapat digunakan aplikasi multiuser [5]. MySQL dapat dilihat pada Figure 9.

[Figure 9 about here.]

\section{METODE PENELITIAN}

\section{Tahap Perencanaan}

Tahap perencanaan meliputi sistem kerja keseluruhan, fitur yang direncanakan sekaligus desain dari sistem Monitoring Pemakaian Air Prabayar Berbasis IoT dan Notifikasi Telegram. Ilustrasi desain sistem dapat dilihat pada Figure 10 di bawah ini.

[Figure 10 about here.]

Berikut merupakan gambar diagram blok pada sistem air prabayar dapat dilihat pada Figure 11 dibawah ini.

[Figure 11 about here.]

a. Sensor Flow meter

Sensor Flow meter untuk mengukur laju air yang mengalir dalam pipa tertutup atau terbuka yang selanjutnya data hasil pembacaannya akan diproses mikrokontroler.

\section{b. Buck Converter}

Rangkaian pengatur switching step-down yang mudah dan aman.

c. Solenoid valve 
Tugas dari solenoid valve adalah untuk membuka/mematikan laju air yang dikontrol oleh program yang dikontrol oleh Arduino.

\section{d. LCD $16 \times 2$}

LCD 16x2 digunakan untuk menampilkan data yang diproses oleh mikrokontroler Arduino Nano dalam hal ini yaitu nilai pemakaian air.

\section{e. ESP8266 Wemos D1}

Berfungsi sebagai pusat kendali utama pengumpulan data-data yang dideteksi oleh sensor dan mengirimkan data-data yang telah dihasilkan oleh sensor tersebut ke dalam server.

\section{f. Website}

Informasi dalam bentuk web yang tergabung di URL yang berisi daftar penghuni kos dan jumlah pemakaian air.

\section{g. Telegram}

Aplikasi untuk mengirim pesan dengan cepat, aman, ringan, mudah dan gratis. Telegram berfungsi sebagai notifikasi kepada penghuni kos apabila kuota air mendekati habis.

\section{h. Arduino Nano}

Arduino Nano merupakan sebuah komponen pemroses data yang diterima dari komponen input dan akan mengubah data tersebut menjadi suatu perintah untuk komponen output. Arduino merupakan komponen utama dalam perancangan yang berfungsi sebagai kontrol pada sensor flow meter dan kuota. Setelah proses inisialisasi, mengalirnya air dikontrol oleh arduino yang dibawahnya ada sensor flow meter untuk menghitung debit air yang mengalir. Selanjutnya kuota diinput untuk menentukan jumlah pemakaian air dan ditampilkan pada LCD secara realtime. Setelah proses penginputan jumlah kuota, maka solenoid valve akan terbuka kemudian air mengalir sesuai kuota. Dimana flowrate yang mengalir dapat mempengaruhi cepat atau lambatnya pengurangan saldo. Kemudian Telegram akan memberi sinyal notifikasi kepada pelanggan apabila kuota akan habis. Untuk merancang program tersebut diperlukan perancangan diagram alir untuk membangun alur sebuah program. Berikut merupakan alir sistem air prabayar dapat dilihat pada Figure 12 .
[Figure 12 about here.]

HASIL DAN PEMBAHASAN

\section{Perancangan Sistem}

Pada perancangan rangkaian Mikrokontroler, akan digunakan Arduino Nano dengan IC Mikrokontroler ATMEGA328. Rangkaian ini terdiri dari Minimum System Mikrokontroler, komunikasi Serm dengan ESP8266, serta konektor dengan module lainnya. Gambar skematik rangkaian mikrokontroler dapat dilihat pada Figure 13.

[Figure 13 about here.]

\section{Perancangan Website}

Tampilan Aplikasi dibagi menjadi beberapa fungsi menu, yaitu Data Penyewa Kos, Setting, dan API (Aplication Programming Interface). Berikut ini tampilan utama dari aplikasi website yang dibuat dapat dilihat pada Figure 14.

[Figure 14 about here.]

Keterangan:

1.Sidebar Menu

2.Tampilan Monitoring Air Prabayar

Dibagian kiri / sidebar terdapat daftar menu yang dapat diakses aplikasi. Dibagian konten adalah tampilan daftar perangkat air prabayar. Data masingmasing perangkat ditampilkan berdasarkan ID Perangkat yang akan diakses oleh perangkat air prabayar.

[Figure 15 about here.]

Pada Figure 15, tampilan web air prabayar dapat memberikan informasi pemakaian air yang digunakan setiap penghuni kos. Data akan dimanfaatkan untuk merekam penggunaan air selama kuota masih ada.

[Figure 16 about here.]

Dari Figure 16, fungsi API tidak memiliki tampilan, namun digunakan untuk memperbarui data dari perangkat air prabayar berdasarkan ID perangkat yang akan diakses menggunakan metode GET dengan pemrograman PHP.

Pengujian Keseluruhan Sistem 
Pengujian dilakukan untuk mendapatkan hasil dari data monitoring dari setiap perangkat berdasarkan ID perangkat yang dimasukan. Pengujian dilakukan menggunakan dua perangkat yang akan diuji berbeda untuk melihat data yang masuk apakah sudah sesuai dengan ID perangkat. Hasil pengujian sesuai dengan hasil pengukuran sensor pada tampilan LCD dan melakukan uji dari notifikasi aplikasi Telegram. Agar hasil data yang diperoleh akurat, pengujian pengukuran data dilakukan selama beberapa kali.

Pengujian ini juga akan menguji hasil pengendalian pemakaian air prabayar dari Aplikasi Telegram dan Website dan menguji Notifikasi dari aplikasi telegram. Berikut ini hasil tampilan perangkat saat bekerja. dapat dilihat pada Figure 17.

\section{[Figure 17 about here.]}

Pengujian bertujuan mengetahui parameterparameter pada sistem monitoring air prabayar berjalan dengan baik. Pengujian sistem ini menggunakan perbandingan dari pengujian alat selama beberapa kali dan menguji notifikasi alat apakah berjalan dengan baik seperti pada table 1 .

[Table 1 about here.]

$$
\text { Tingkat akurasi }=\frac{\text { Volume air gelas ukur }}{\text { Jumlah percobaan }}
$$

Rata-rata toleransi $=100-$ Tingkat akurasi

Tabel uji beda rata-rata menggunakan metode Independen Sample T-Test ditunjukan pada table 2.

[Tabel 2 about here.]

Berdasarkan keterangan pada tabel 2, pengujian perbedaan rata-rata volume air dengan Gelas Ukur dan Sensor Flow Meter menghasilkan nilai signifikansi sebesar 0,352. Hal tersebut diketahui bahwa nilai signifikansi > alpha sebesar 0,05, sehingga H0 diterima. Oleh karena itu dapat dinyatakan bahwa nilai volume air, Kelompok Gelas Ukur dan Kelompok Sensor Flow Meter adalah tidak berpengaruh secara signifikan.

\section{KESIMPULAN}

Setelah melalui beberapa pengujian setiap komponen hingga pengujian keseluruhan sistem rancang bangun monitoring pemakaian air prabayar berbasis IoT dan notifikasi Telegram, maka kesimpulan yang dihasilkan sebagai berikut:

- Perangkat mampu mengirimkan data pada webserver dan notifikasi telegram

- Perangkat mampu dikendalikan melalui jaringan internet dengan menggunakan web server ataupun melalui chatbot aplikasi telegram.

- Kontroller ATMEGA32 dan ESP8266 yang terkoneksi jaringan wifi dapat mengirim data dengan tingkat keberhasilan $\pm 98 \%$.

\section{SARAN}

Berdasarkan hasil percobaan dan analisa di atas dapat diberikan saran sebagai berikut :

- Pembuatan mekanis sensor dengan desain dan bahan yang baik, agar tingkat pembacaan sensor dan ketahanan alat.

- Penggunaan Cloud Server, selain sensor dapat diakses melalui Internet, juga dapat meminimalisir terjadinya server down.

- Pengembangan aplikasi Android khusus, agar meningkatkan tingkat keamanan data dari kejahatan.

- Pada alat ini masih terdapat kelemahan yaitu Solenoid valve cepat panas. Pengembangan tahap selanjutnya bisa menggunakan Solenoid 2 katup.

\section{DAFTAR PUSTAKA}

[1] R. Pradisti, J. T. Komputer, and P. N Sriwijaya, "Rancang Bangun Alat Penghitung Biaya Penggunaan Listrik Kamar Kos Secara Otomatis Berbasis Arduino Menggunakan Sensor Arus," vol. 12, no. x, pp. 95-102, 1978.

[2] T. Suryanto, M. Juhan Dwi, Rijanto, "Rancang Bangun Alat Pencatat Biaya Pemakaian Energi Listrik pada Kamar Kos Menggunakan Modul Global System For Mobile Communications (GSM) 800L Berbasis Arduino Uno," Jur. Tek. Elektro, vol. 8, pp. 47-55, 2019.

[3] P. Sokibi, "Perancangan Sistem Monitoring Perangkat Jaringan Berbasis ICMP dengan Notifikasi Telegram,” vol. 02, no. 02, 2017.

[4] 2017 Limantara, dkk, "Pemodelan Sistem Pelacakan LOT Parkir Kosong Berbasis Sensor Ultrasonic Dan Internet Of Things ( 


\section{Journal of Electrical and Electronic Engineering-UMSIDA \\ ISSN 2460-9250 (print), ISSN 2540-8658 (online) \\ Vol. 5, No. 2, October 2021}

IOT ) Pada Lahan Parkir Diluar Jalan," Semin. Nas. Sains dan Teknol., vol. 1, no. 2, pp. 1-10, 2017.

[5] M. Destiningrum and Q. J. Adrian, "Sistem Informasi Penjadwalan Dokter Berbassis Web Dengan Menggunakan Framework Codeigniter (Studi Kasus: Rumah Sakit Yukum Medical Centre)," J. Teknoinfo, vol. 11, no. 2, pp. 30-37, 2017, [Online]. Available: https://ejurnal.teknokrat.ac.id.

[6] D. P. Buwana, S. Setiawidayat, and M. Mukhsin, "Sistem Pengendalian Lampu Penerangan Jalan Umum (PJU) Melalui Jaringan Internet Berbasis Android," JOINTECS (Journal Inf. Technol. Comput. Sci., vol. 3, no. 3, pp. 287-292, 2018, doi: 10.31328/jointecs.v3i3.820.

[7] F. Sirait, F. Supegina, and I. I. Septian, "Peningkatan Efisiensi Sistem Pendistribusian Air Dengan Menggunakan Iot ( Internet Of Things )," J. Teknol. Elektro, Univ. Mercu Buana, vol. 8, no. 3, pp. 234-239, 2017.

[8] A. Iwan and A. Setiyadi, "Untuk Produksi Taoge Berbasis Internet of Things," Stud. Kasus Di Blok Taoge Kota Cimahi, pp. 1-8.

[9] R. Tullah, Sutarman, and A. H. Setyawan, "Sistem Penyiraman Tanaman Otomatis Berbasis Mikrokontroler Arduino Uno Pada Toko Tanaman Hias Yopi,' J. Sisfotek Glob., vol. 9, no. 1, pp. 100-105, 2019.

[10] R. P. W. Putra, M. Mukhsim, and F. Rofi'i, "Sistem Pemantauan Dan Pengendalian Modul Automatic Transfer Switch (ATS) Melalui Android Berbasis Arduino," TELKA Telekomun. Elektron. Komputasi dan Kontrol, vol. 5, no. 1, pp. 43-54, 2019, doi: 10.15575/telka.v5n1.43-54.

[11] A. Brahmantika, "Sistem Otomatisasi Budidaya Tumbuhan Aquascape Berbasis Arduino UNO," in Seminar Hasil Elektro S1 ITN Malang, 2019, pp. 1-14. 


\section{Journal of Electrical and Electronic Engineering-UMSIDA \\ ISSN 2460-9250 (print), ISSN 2540-8658 (online) \\ Vol. 5, No. 2, October 2021}

\section{DAFTAR TABEL}

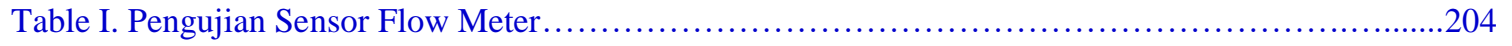

Table II. Uji beda rata-rata menggunakan metode Independen Sample T-Test .....................206 
Table I. Pengujian Sensor Flow Meter

\begin{tabular}{|c|c|c|c|}
\hline No & $\begin{array}{l}\text { Jumlah } \\
\text { Air } \\
\text { (Liter) }\end{array}$ & $\begin{array}{l}\text { Durasi } \\
\text { (Detik) }\end{array}$ & $\begin{array}{c}\text { Total Debit Air } \\
\text { Pada Gelas Ukur } \\
\text { (Ml) }\end{array}$ \\
\hline 1 & 1 Liter & 40 & 990 \\
\hline 2 & 1 Liter & 41 & 980 \\
\hline 3 & 1 Liter & 42 & 990 \\
\hline 4 & 1 Liter & 40 & 980 \\
\hline 5 & 1 Liter & 41 & 1000 \\
\hline 6 & 1 Liter & 39 & 975 \\
\hline 7 & 1 Liter & 42 & 1000 \\
\hline 8 & 1 Liter & 39 & 990 \\
\hline 9 & 1 Liter & 39 & 1000 \\
\hline 10 & 1 Liter & 41 & 980 \\
\hline 11 & 1 Liter & 39 & 1000 \\
\hline 12 & 1 Liter & 40 & 980 \\
\hline 13 & 1 Liter & 39 & 990 \\
\hline 14 & 1 Liter & 40 & 1000 \\
\hline 15 & 1 Liter & 42 & 990 \\
\hline 16 & 1 Liter & 40 & 990 \\
\hline 17 & 1 Liter & 41 & 990 \\
\hline 18 & 1 Liter & 40 & 970 \\
\hline 19 & 1 Liter & 39 & 990 \\
\hline 20 & 1 Liter & 41 & 980 \\
\hline 21 & 1 Liter & 40 & 980 \\
\hline
\end{tabular}




\begin{tabular}{|c|c|c|c|}
\hline 22 & 1 Liter & 40 & 1000 \\
\hline 23 & 1 Liter & 39 & 1000 \\
\hline 24 & 1 Liter & 42 & 980 \\
\hline 25 & 1 Liter & 39 & 1000 \\
\hline 26 & 1 Liter & 40 & 990 \\
\hline 27 & 1 Liter & 40 & 970 \\
\hline 28 & 1 Liter & 39 & 1000 \\
\hline 29 & 1 Liter & 41 & 990 \\
\hline 30 & 1 Liter & 40 & 990 \\
\hline \multicolumn{3}{|c|}{ Rata-Rata Toleransi } & 1.2 \\
\hline \multicolumn{3}{|c|}{ Tingkat Akurasi } & 98,8 \\
\hline
\end{tabular}




\section{Journal of Electrical and Electronic Engineering-UMSIDA \\ ISSN 2460-9250 (print), ISSN 2540-8658 (online) \\ Vol. 5, No. 2, October 2021}

Table II. Uji beda rata-rata menggunakan metode Independen Sample T-Test

\begin{tabular}{|l|c|c|c|c|c|}
\hline & $N$ & Mean & Signifikasi & Keterangan & Kesimpulan \\
\hline Gelas Ukur & 30 & 80134 & \multirow{2}{*}{0.352} & sig $>0.05$ & $\begin{array}{c}\text { Tidakberpengaruh } \\
\text { signifikan }\end{array}$ \\
\hline Durasi & 30 & 89430 & & &
\end{tabular}




\section{Journal of Electrical and Electronic Engineering-UMSIDA \\ ISSN 2460-9250 (print), ISSN 2540-8658 (online)

\section{DAFTAR GAMBAR}

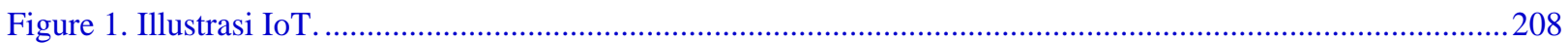

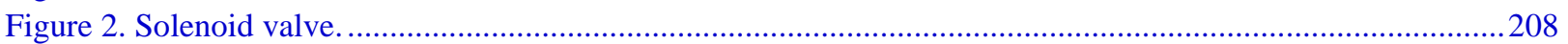

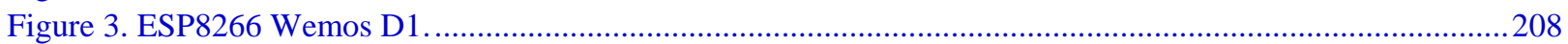

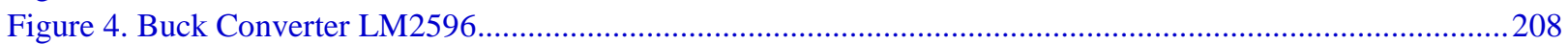

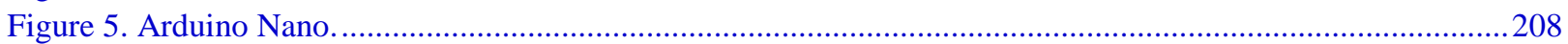

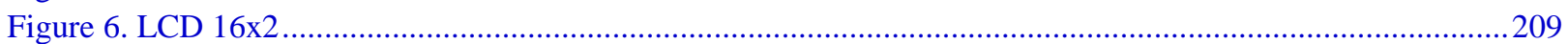

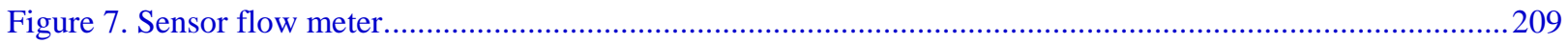

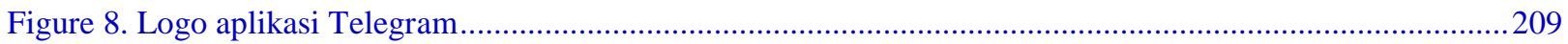

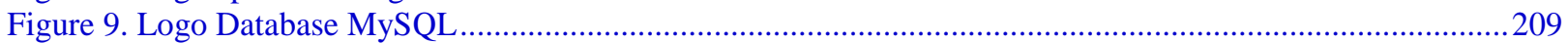

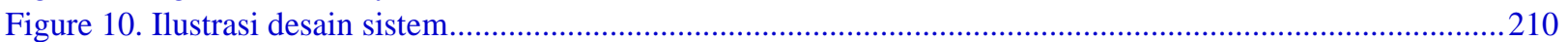

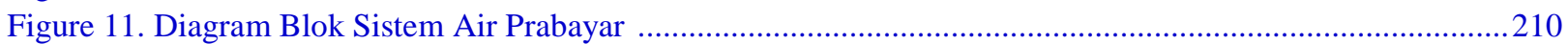

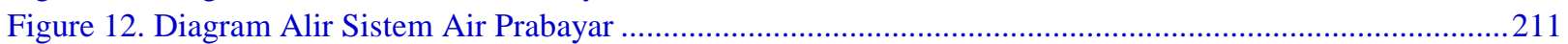

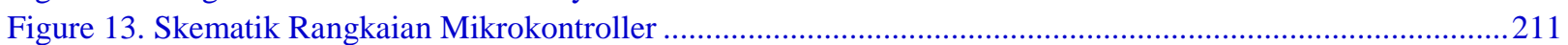

Figure 14. Hasil Tampilan Halaman Utama Web .......................................................................................2 212

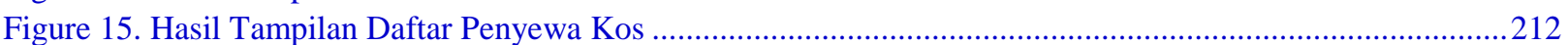

Figure 16. Hasil Tampilan Menu Update Data dan Penambahan Kuota ..........................................................212

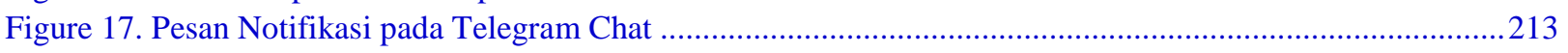




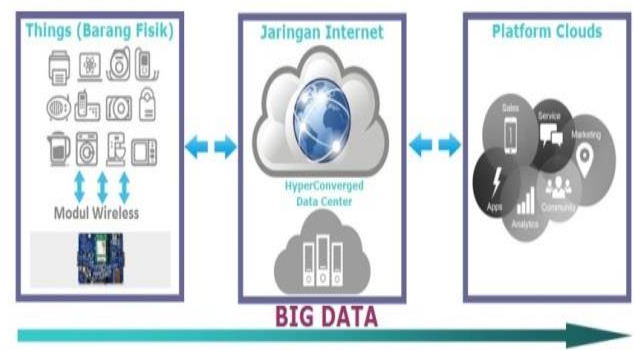

Figure 1. Illustrasi IoT

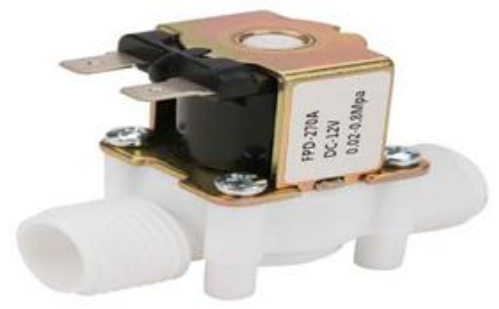

Figure 2. Solenoid valve

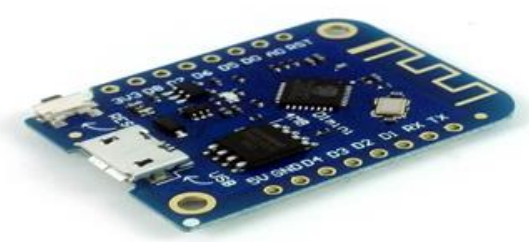

Figure 3. ESP8266 Wemos D1

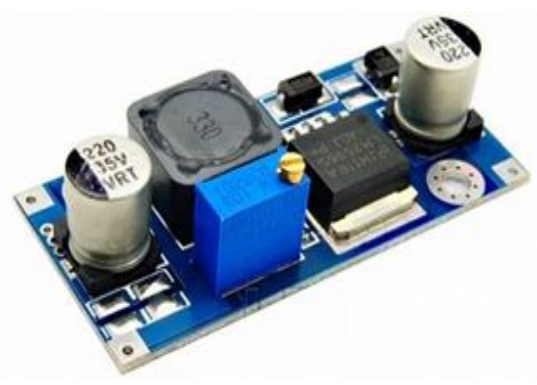

Figure 4. Buck Converter LM2596 


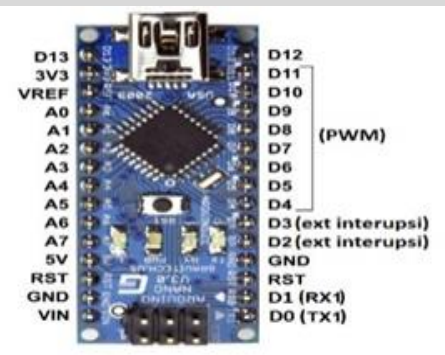

Figure 5. Arduino Nano

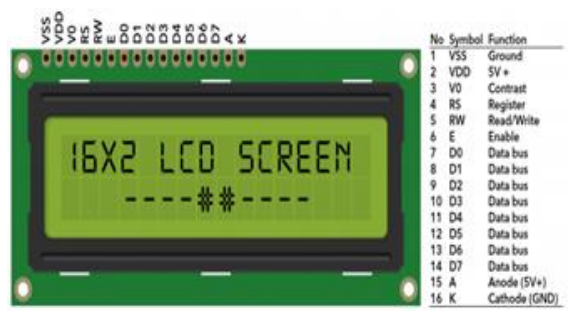

Figure 6. LCD 16x2

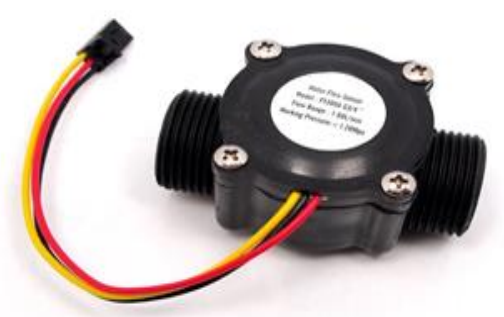

Figure 7. Sensor flow meter

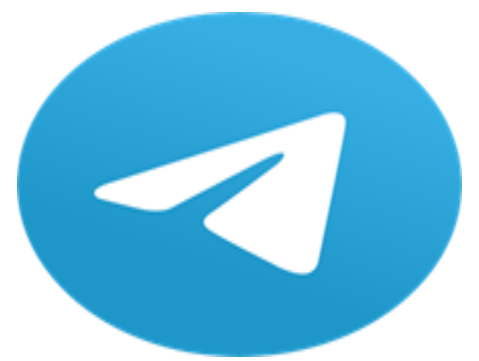

Figure 8. Logo aplikasi Telegram 


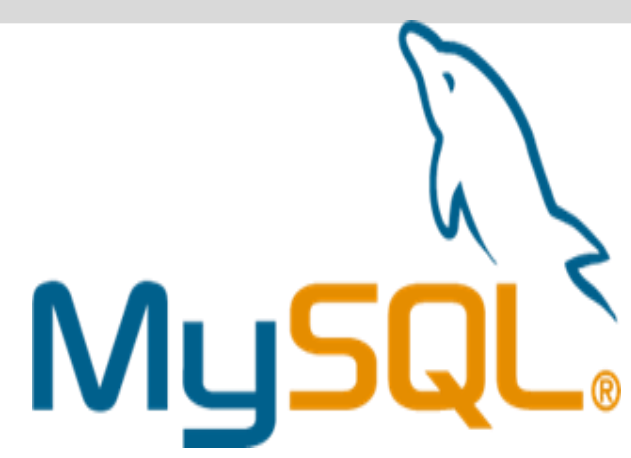

Figure 9. Logo Database MySQL

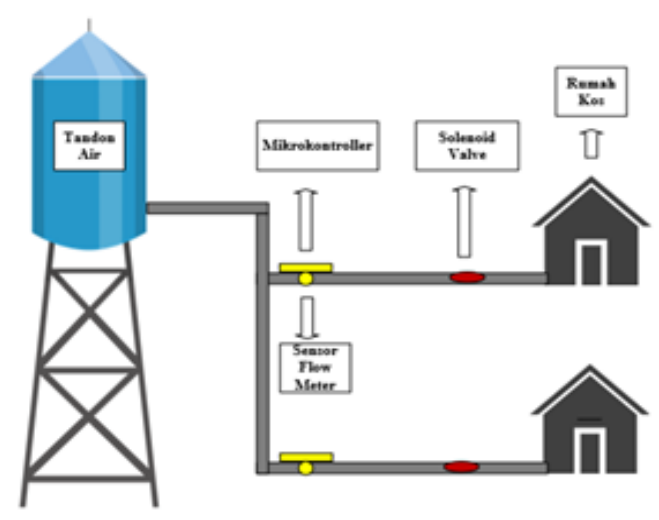

Figure 10. Ilustrasi desain sistem

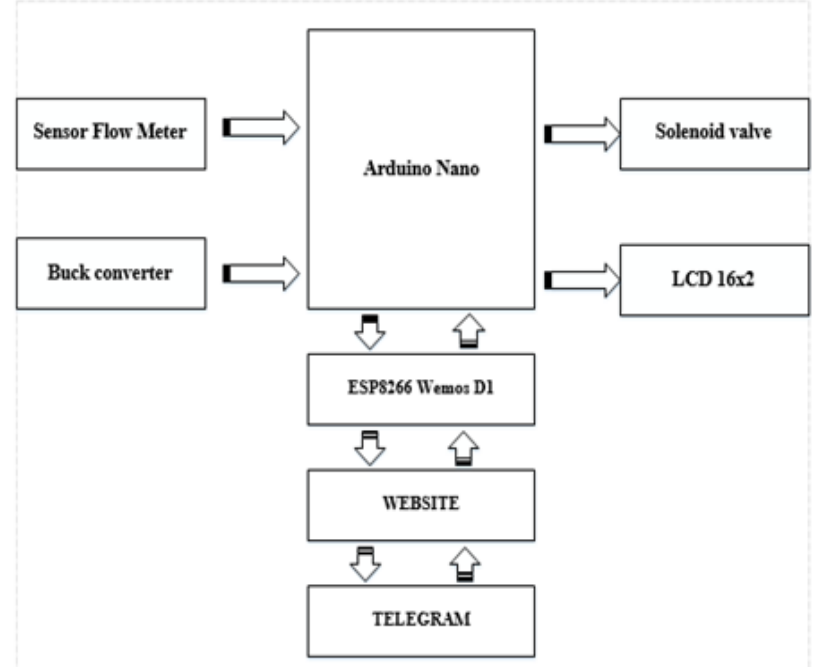

Figure 11. Diagram Blok Sistem Air Prabayar 
$T 7 \begin{aligned} & \text { Journal of Electrical and Electronic Engineering-UMSIDA } \\ & \text { ISSN 2460-9250 (print), ISSN 2540-8658 (online) }\end{aligned}$

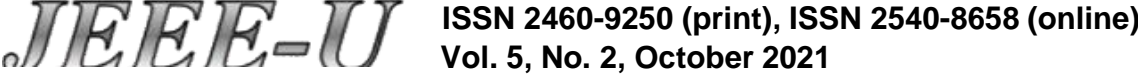

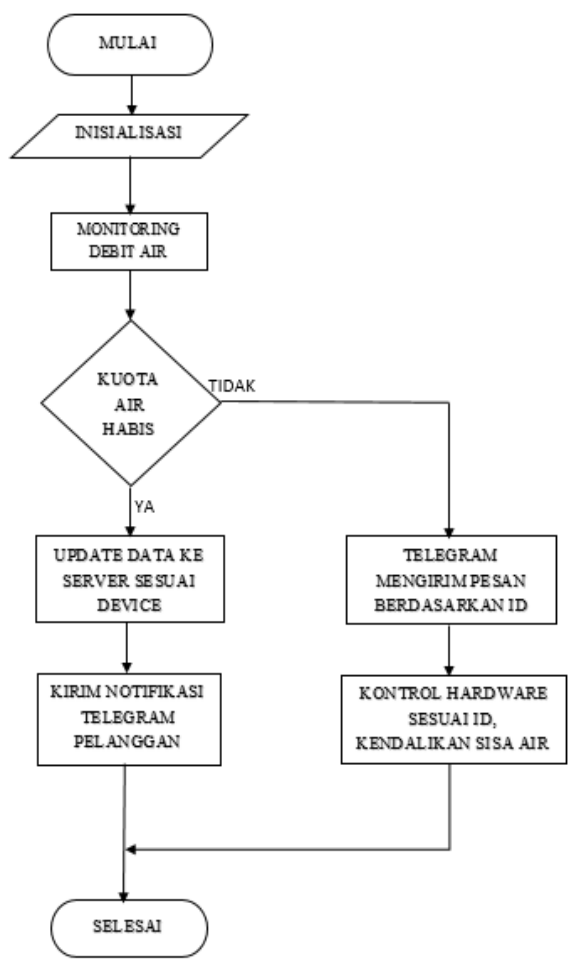

Figure 12. Diagram Alir Sistem Air Prabayar

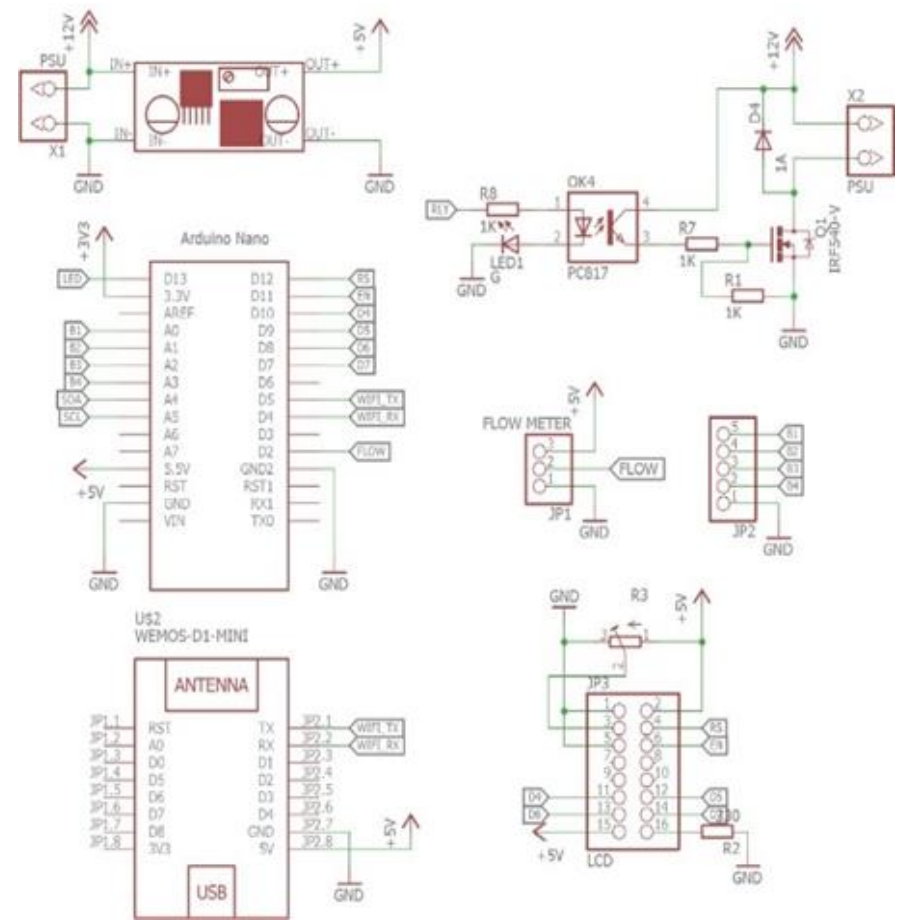

Figure 13. Skematik Rangkaian Mikrokontroller 


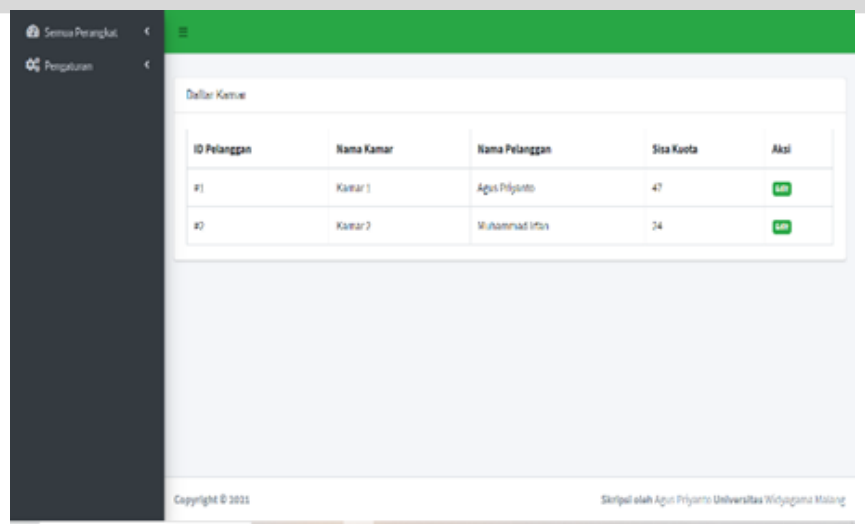

Figure 14. Hasil Tampilan Halaman Utama Web

\begin{tabular}{|l|l|l|l|l|}
\hline Sistem Air Prabayar & & & \\
\hline Daftar Kamar & & & & \\
\hline ID Pelanggan & Nama Kamar & Nama Pelanggan & Sisa Kuota & Aksi \\
\hline$\# 1$ & Kamar 1 & Agus Priyanto & 33 & Edit \\
\hline$\# 2$ & Kamar 2 & Muhammad Irfan & 48 & Edit \\
\hline
\end{tabular}

Figure 15. Hasil Tampilan Daftar Penyewa Kos

Update Data
ID Peranglat
$\# 1$

Nama Ruang

న $\operatorname{Kamar} 1$

Nama Pelanggan

2 Agus Priyanto

Chat ID Telegram (Pelanggan)

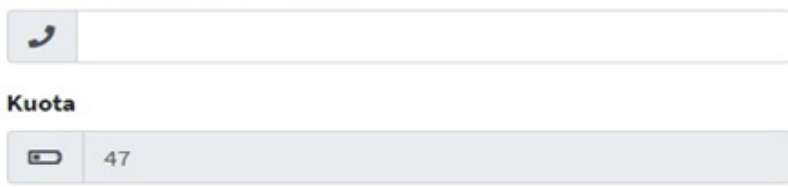

Tambah Kuota (Cek Kuota Perangkat + Tambah Kuota $=$ Hasil) (0) 
Figure 16. Hasil Tampilan Menu Update Data dan Penambahan Kuota

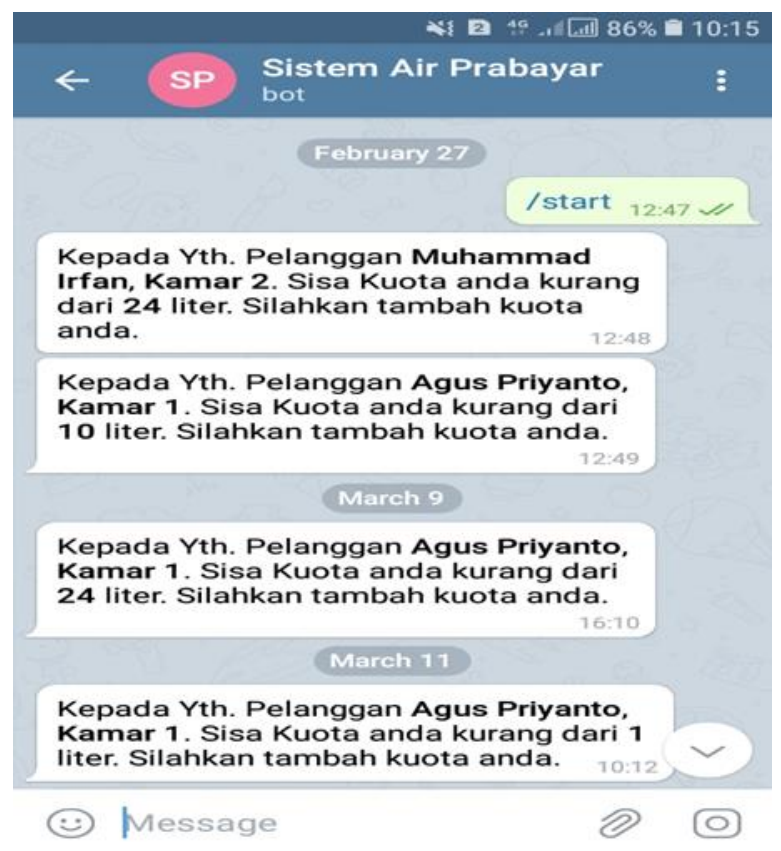

Figure 17. Pesan Notifikasi pada Telegram Chat 